\title{
A review: Fast Repair Technology of Cement concrete pavement
}

\author{
Zhao Zhiqin $^{1}$, Ma Qingna ${ }^{2 *}$ Xu Qian ${ }^{3}$, Sun Feng ${ }^{4}$ \\ 1,2,3,4 College of Filed Engineering, Army Engineering University of PLA, Nan Jing, Jiangsu, 210000, China
}

\begin{abstract}
Cement concrete pavement Road always damaged under the pressure of traffic, so fast repair technology of cement concrete pavement was an urgent need to be studied. The author introduced the new rapid repair technology of cement concrete pavement from the concrete materials, mixture design, and construction equipment.
\end{abstract}

\section{Introduction}

In the process of cement concrete pavement construction, it was found that road built in the 1990s and early 21 st century were different degree of deformation, fracture and damage just after used 3 7 years with the increase of the traffic, but the lack of method of design, material selection, construction technology, construction quality supervision and control should also take charge ${ }^{[1]}$.

Because road network traffic was like the blood vessel to economy, so close the traffic for a long time repair was unaccepted, pavement that need to repaired should be put into use in the shortest time. As a result, fast repair technology of cement concrete pavement was an urgent need to be studied. This paper presented the fast repair technology from two aspects, material and construction, introduced new technology at home and abroad, forecasted the development trend of the technology in future.

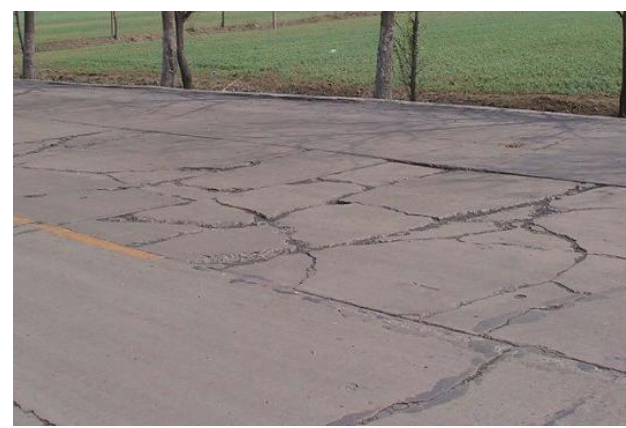

Figure 1.-concrete crack

\section{Definition}

At present, the cement concrete pavement fast repair technology in China are often under the premise of without changing the construction technology, by selecting high quality cement base material and appropriate kinds of admixtures, reducing water cement ratio of concrete, adjusting the mixing proportion of concrete, so as to improve the compactness of concrete, to reinforce the interface bonding between cement and aggregate, the technology need 3 7 days before open traffic. However, many actual repair projects, especially in highway, 3 7 days' interrupted traffic was hard to be accepted. Therefore, the traffic interval should be shorter, so we need new technology. New technology of cement concrete pavement was described and prospect ${ }^{[2]}$. Fig.1 show the pavement distress - concrete crack. Fig.2 show the the pavement distress - spongy surface. Fig. 3 show different stage of pavement repair project.

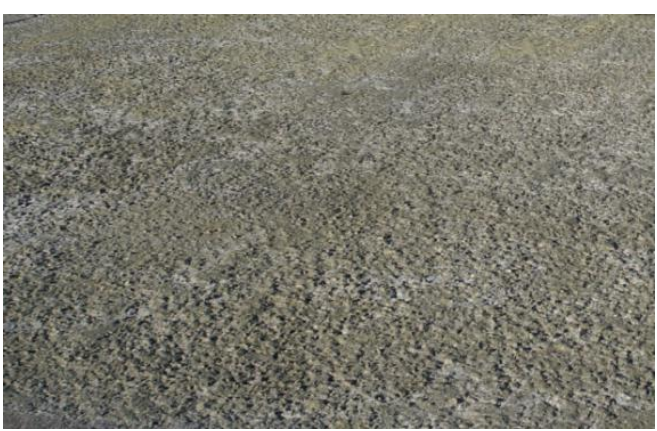

Figure 2. - spongy surface 


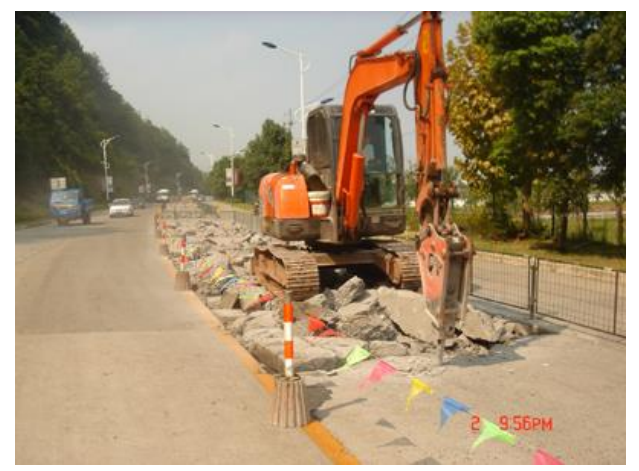

(a) Breaking the original pavement Figure 3. - different stage of pavement repair project

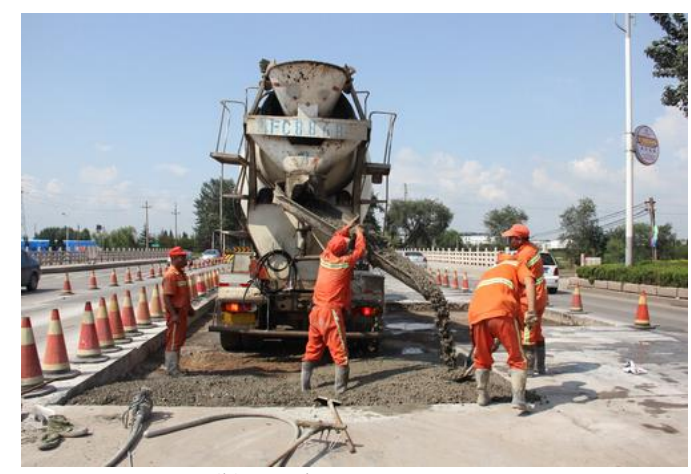

(b)pouring new concrete

\section{Concrete Raw Materials}

\subsection{Cement.}

Cement was the most active constituent materials in concrete. Selection and reasonable use of cement was the key to obtain high quality concrete. As for rapid repair project, fast setting or rapid hardening cement commonly were used abroad. Japan widespread used sprayed concrete which the final setting time was $15 \mathrm{~min}$ while ordinary Portland cement was $190 \mathrm{~min}$. Concrete with the sprayed concrete soaked $0.3 \%$ retarder, the initial setting time was 40 min while common concrete need $300 \mathrm{~min} ; 1$ day bending strength can reach $4.1 \mathrm{MPa}$, 1day tensile strength can reach $2.5 \mathrm{MPa}$. The pavement repair project used the cement can restore the traffic within $12 \mathrm{~h}$ in Japan. Similarly, US exploit one kind blended cement named Pyrament, which the $4 \mathrm{~h}$ compressive strength was about 3.4Mpa, 1 day compressive strength was above $13.4 \mathrm{MPa}$, 28 day can reached $82.7 \mathrm{MPa}$. Meanwhile, the two cement was expensive than regular cement about 5 10 times ${ }^{[3]}$.

\subsection{Synthetic Aggregate, Recycled Aggregate.}

Swelling soil and shale by heat treatment can produce light aggregate, which had porous structure and cell wall structure that can make the concrete had ideal anti-sliding performance. Ceramic aggregate is another kind of synthetic aggregate, through ceramics technology processing, can be used as aggregate against sliding. Due to the high cost of synthesis of aggregate, widely using the material in pavement repair engineering should study how to reduce the cost.

Using recycled aggregates, by recycling old concrete pavement or asphalt concrete pavement and through regeneration technology, the recycled aggregate were more economic than deal with these waste materials in some areas, and certain also more beneficial to the environment.

\subsection{Admixture.}

Among fast repair technology, the most used admixture were coagulating agent and early strength agent, which can speed up the strength of concrete in early age, reducing the setting time of concrete. Calcium chloride was one of the most commonly used coagulant. In the process of calcium chloride was widely used, people found that calcium chloride corroded reinforced steel among concrete structures Then, coagulant did not contain calcium chloride, such as sulphate, formic acid salt, nitrite was used in construction.

Early strength can improve cement concrete early strength to reach the standard of construction in. Using early strength agent can not only ensure the quality of road and bridge, durability of the engineering, but also help to accelerate the speed of road and bridge repair engineering, making road and bridge to recover to the normal use of state as soon as possible, reducing the traffic jam caused by road and bridge damage. Experimental research showed that if we add steel structure, wood, fiber materials such as carbon into concrete, which can effectively prevent the cracking of concrete, reduced the deformation degree of concrete, reduced shrinkage and penetration ability of concrete, improving the strength of the concrete. Another study showed that using fiber material as road and bridge maintenance material can significantly improve materials' mechanical properties and physical properties.

\subsection{Mix proportion.}

With the requirement of engineering technology and the development of computer technology, the development in the field of concrete mix proportion design focused on the following aspects:1)Through develop of computer aided technology to simplify the standard procedure;2) Using more mineral mixture and admixture in the mix proportion design;3)Developing new mix proportion theory, focus on study the aggregate gradation and its influence on performance. Developing software system of mix proportion was an important development direction in the future, which should be built on successful experience, the particle size distribution and the model of rheological theory. The system can predict the workability, strength and durability more accurately based on input material properties, environment and load conditions. The system can automatically select the appropriate materials and mix proportion to determine the most economic with complied all input conditions[3]. 


\subsection{New Materials.}

The United States, Japan had been widely used cement mortar mixed with polymer. For example, synthetic polymer and tar were applied on pavement with wider fracture.

Fiber reinforced concrete used to repair currently include steel fiber reinforced concrete, carbon fiber reinforced concrete and synthetic fiber reinforced concrete $^{[4]}$. At present, some application of plant fiber reinforced concrete had appeared, the application of polymer cement coagulation also became more popular. Steel fiber reinforced concrete was a new kind composite materials with excellent properties ${ }^{[5]}$. Compared with ordinary concrete, the properties of tensile, anti-bending, crack resistance and abrasion resistance, impact resistance, fatigue resistance, toughness were improved significantly. It can reduce the thickness of surface layer, increase contraction joint spacing, improve pavement performance and prolong the service life of pavement.

Concrete mixed with silica fume had extremely strong pozzolanicity, it had high early strength and perfect post strength development. So the bond between old and new concrete was satisfactory. Using the concrete in bridge deck pavement repair project can open traffic faster and the repaired structure has high structural strength and good durability. Figure 4 show polymer mortar and steel fiber reinforced concrete.

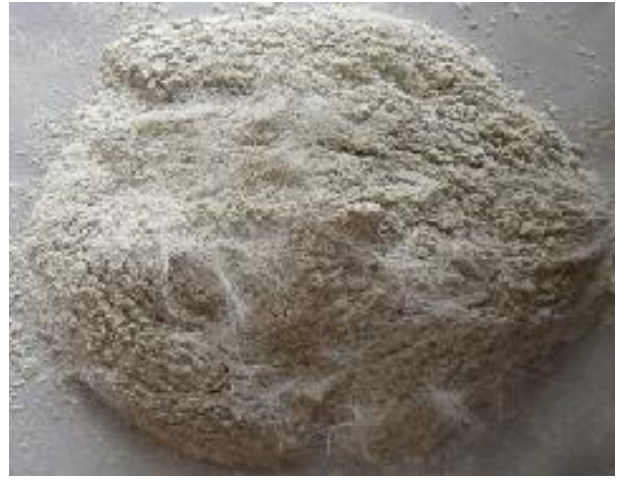

(a)polymer mortar

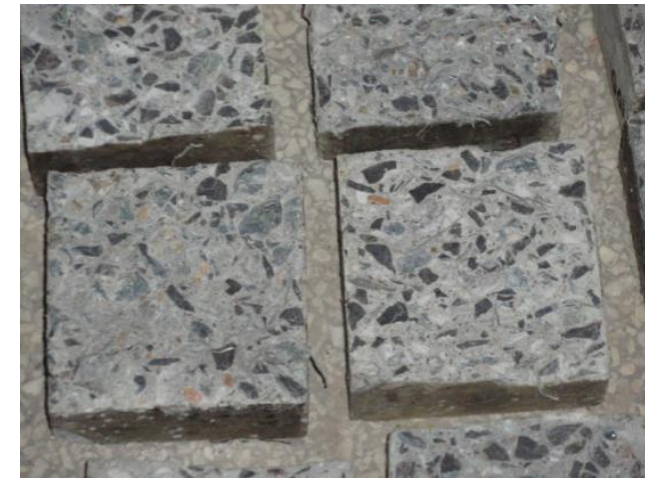

(b)steel fiber reinforced concrete

Figure4. - new construction material

\section{Construction Equipment}

With the popularization and application of pavement slipform technology, new type of construction equipment had get positive development and research in repair technology. The United States put forward a new type of paver, called zero lateral pitch paver $(\mathrm{ZCP})^{[6]}$, ZCP had special significance in the repair and reconstruction

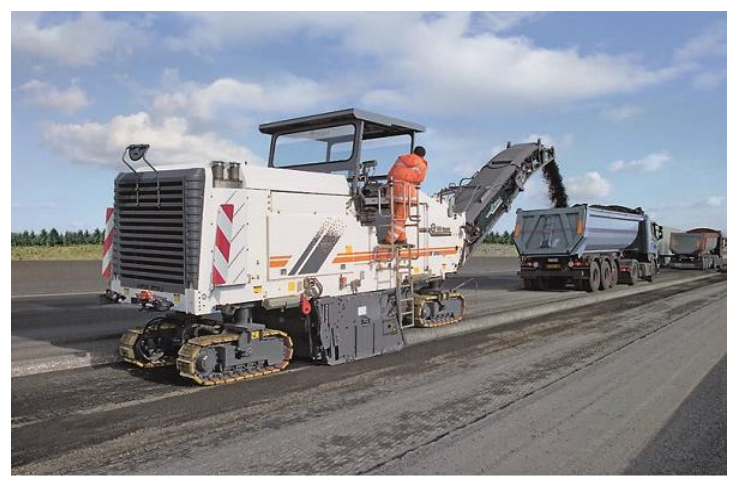

(a) Cold Milling Machine (Wirtgen) engineering. The purpose was to limit paver in the maintenance driveway so make the adjacent lanes' traffic continue. ACI (American Concrete Institute) learned a method that can realize this goal preliminary, through improve ordinary concrete paver, taken out a set of tracks and extended another set of track forward [7]. As improvement and innovation, the technology had a broad application prospects. Figure 5 show new construction equipment.

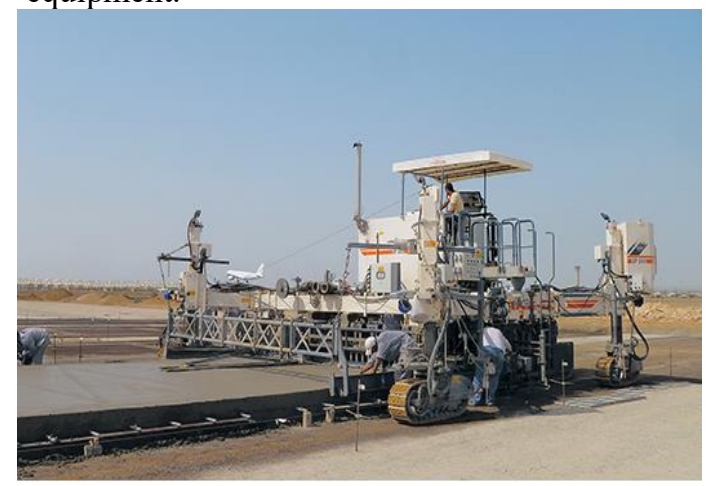

(b) ZCP Paver (Wirtgen) Figure 5. - construction equipment

\section{Conclusions}

Fast repair technology of cement concrete pavement was important to economic, we can develop the technology from new material design, concrete mix proportion, new construction equipment. The equipment's progress decide the whole technology to some extent, so the researcher should work with machinery manufacture company to change the world.

\section{Acknowledgments}

This work was financially supported by the program of Engineering Academy of People's Liberation Army, 
Engineering equipment operational application data resources construction.

\section{References}

1. Luo Zhu,Fu Zhi,Fan, Xiaoxiang. Study on 12-hour Quick repair Technology of Cement Concrete Pavement [J]. Western China, 2006(3).

2. Wang Tingting. Researeh on Fast Repair and Regeneration Technology of Cement Concrete Pavement [D]. Changan University, 2011.

3. Zhong Deming. Stress Analysis and Numerical of Asphalt Cement Concrete Pavement on Layer Old Cement Road [D]. Nanhua University, 2014.

4. Lu Yijing. Research of Cement concrete pavement coagulation ice damage protection and restoration technology [D]. Tongji University, 2014.

5. Wu Bin. Experimental Study for Dynamic Response of Foundation by impact Rolling [D]. Changsha University of Science and Technology, 2008.

6. An Exploration into the Techniques for the PostDisaster Rush-Repair of High-Speed Railway Bridges and Recovery Techniques for Them.

7. An Exploration into the Emergency Support for Concrete Bridges of High-Speed Railways. 